\title{
Experimental Study on Compressive Property of Cemented Soil with
}

\section{Basalt Fiber}

\section{Feng Chen}

\author{
Fujian Province Collaborative Innovation Center for Environmentally Friendly and Energy Saving \\ High Performance Concrete, Fujian Jiangxia University, Fuzhou, Fujian, 350108, China \\ cfxh@fjjxu.edu.cn
}

Keywords: cemented soil, basalt fiber, compressive property, proportions

Abstract. To enhance the mechanical performance of cemented soil, this paper discusses the way of improving the mechanical performance by incorporating basalt fiber into cemented soil. Unconfined compressive strength test is conducted on cemented soil with basalt fiber of different proportions, and the results show that the incorporation of basalt fiber can significantly improve the compressive strength of the cemented soil samples at different agess, but its strengthening effects weaken steadily with the increase of fiber amount. The incorporation of basalt fiber can enhance the plasticity of cemented soil, and the sample at its peak stress can still bear some loading, with some residual strength existing, propitious for the enhancement of engineering safety and stability. Additionally, the relations between the compressive strength and ages of cemented soil with basalt fiber of different proportions are established based on the experiment results, which can provide some references for practical projects.

\section{Introduction}

In recent years, with the rapid development of underground engineering, cemented soil, with the superiorities of low compressibility and permeability, has been extensively applied in projects like foundation reinforcement, waterproof curtain, slop reinforcement and stabilization and deep foundation pit support. However, the strength of cemented soft soil is low and can hardly meet the strength requirements, so how to improve strength has become a hot study topic. Besides the traditional methods, the method of incorporating fiber into cemented soil to enhance its strength is proposed in some study. Yin Yong adopted glass fiber to improve the mechanical performance of cemented soil; Nilo Cesar Consoli performed unconfined compressive strength test on fiber cemented soil and found the incorporation of fiber enhanced the compressive strength of cemented soil; Consoli took the impacts of fiber incorporation within wide cementation range into consideration. Basalt fiber has been considered as high performance concrete strengthening material for quite good mechanical performance and cost performance. Therefore, this paper studies the compressive property of the cemented soil sample with different basalt fiber incorporation at different ages but with the same cement proportion ratio. 


\section{Experiment Preparation}

\section{Experimental Materials}

The soil material used in this experiment is the common mud clay in coast area, and its basic physical mechanical performance is as shown in Table 1. The cement adopted is the common 42.5 Portland cement. The fiber is chopped strand of basalt fiber, with the main physical performance shown in Table 2.

Table 1 Physico-mechanical indices of soft soil

\begin{tabular}{|c|c|c|c|c|c|c|c|c|}
\hline$\omega(\%)$ & $\mathrm{V}\left(\mathrm{kN} / \mathrm{m}^{3}\right)$ & $\mathrm{e}$ & $\mathrm{W}_{\mathrm{L}}(\%)$ & $\mathrm{W}_{\mathrm{P}}(\%)$ & $\mathrm{I}_{\mathrm{P}}(\%)$ & $\mathrm{I}_{\mathrm{L}}$ & $\mathrm{C}(\mathrm{kPa})$ & $\Phi\left(^{\circ}\right)$ \\
\hline 54.5 & 16.2 & 1.499 & 45.1 & 20.8 & 24.3 & 1.39 & 9.0 & 6.5 \\
\hline \multicolumn{9}{|c|}{ Table 2 Performance index of basalt fiber } \\
\hline material & $\operatorname{density}\left(\mathrm{kg} / \mathrm{m}^{3}\right)$ & & $r(\mu \mathrm{m})$ & $\begin{array}{r}\text { tensile st } 1 \\
\text { (MP. }\end{array}$ & & $\begin{array}{l}\text { elasticity modulus } \\
\text { (GPa) }\end{array}$ & \multicolumn{2}{|c|}{$\begin{array}{c}\text { elongation at break } \\
(\%)\end{array}$} \\
\hline basalt fiber & 2650 & & & $4150 \sim$ & & $93 \sim 110$ & \multicolumn{2}{|c|}{3.1} \\
\hline
\end{tabular}

\section{Experimental Scheme}

The compressive test adopts the cubic sample of $70.7 \times 70.7 \times 70.7 \mathrm{~mm}^{3}$, which is to be damaged by a press loading at an accelerating rate of $0.15 \mathrm{kN} / \mathrm{s}$, the failure load is recorded and transferred to be the compressive strength of the sample, and the impacts of basalt fiber incorporation amount on the compressive strength are studied through the equal increment $(0.5 \%)$ of basalt fiber amount. The moisture content of soil sample is set according to the original soil, and the mixing ratios of cemented soil are $15 \%$ and $16.5 \%$, with four groups of $15 \%$ (A, C, D, E), one group of $16.5 \%$ (B) and the water-cement ratio of 0.5 . For each proportion pair, three samples are made to be maintained at 7d, 28d, 60d and 90d.

\section{Experiment Results and Analysis}

\section{The Relationship between Basalt Fiber Incorporation Amount and Compressive Strength of Cemented Soil}

In processing the experimental results, the average value of the failure load of the three parallel specimen of each group is selected and the formula (1) is applied to calculate the compressive strength of the cemented soil sample with basalt fiber, with the calculation results presented as shown in Table 3.

$$
f_{c u}=\frac{P}{A}
$$

\section{(1)}

$P$ is the failure load ( $\mathrm{N}$ ) and $A$ is the compressive floorage of the sample $\left(\mathrm{mm}^{2}\right)$ 
Table 3 Test result of unconfined compressive strength

\begin{tabular}{ccccc}
\hline number & $\begin{array}{c}\text { compressive } \\
\text { strength(7d) } \\
(\mathrm{MPa})\end{array}$ & $\begin{array}{c}\text { compressive } \\
\text { strength(28d) } \\
(\mathrm{MPa})\end{array}$ & $\begin{array}{c}\text { compressive } \\
\text { strength(60d) } \\
(\mathrm{MPa})\end{array}$ & $\begin{array}{c}\text { compressive } \\
\text { strength(90d) } \\
(\mathrm{MPa})\end{array}$ \\
\hline A & 0.84 & 1.58 & 2.21 & 2.52 \\
B & 1.01 & 1.85 & 2.54 & 2.76 \\
C & 0.98 & 1.88 & 2.75 & 3.02 \\
D & 1.11 & 2.03 & 2.90 & 3.14 \\
E & 1.19 & 2.14 & 3.01 & 3.25 \\
\hline
\end{tabular}

It can be seen from Table 3 that the incorporation of basalt fiber has somewhat significant strengthening effects on the compressive strength of cemented soil, which is analyzed in detail as follows:

(1) At the ages of 7d, the experimental results show that the increase of cement and basalt fiber incorporation greatly enhances the compressive strength of cemented soil. The compressive strength of sample D, with the cement incorporation of $15 \%$ and the basalt fiber incorporation of $1 \%$, has exceeded that of sample B, only with the cement incorporation of $16.5 \%$, by $9.9 \%$, indicating that under the same circumstance basalt fiber has better strengthening effects on compressive strength of cemented soil than cement incorporation. Sample C and D, with the same cement incorporation ratio $(15 \%)$ and different basalt fiber incorporation ratios $(0.5 \%, 1.0 \%, 1.5 \%)$.

It can be concluded that the equal increment of basalt fiber incorporation has different strengthening efficiencies of compressive strength of cemented soil at each stage. With the first $0.5 \%$ basalt fiber increment, basalt fiber has the greatest increment of compressive strength and the growth rate of compressive strength slowly decreases with the increases of its equal increment.

(2) At $28 \mathrm{~d}$ ages, the experimental results show that compared to at $7 \mathrm{~d}$ ages cemented soil sample $\mathrm{C}$, with cement incorporation of $15 \%$ and basalt fiber incorporation of $0.5 \%$, has the compressive strength higher than sample B, only with cement incorporation of $16.5 \%$, indicating that with the increase of ages the extent of hydration betters, the friction between cemented soil and fiber greatly enhances, and fiber reinforcement effects can be well demonstrated. In the same way, the compressive strength of cemented soil will enhance with the increase of fiber incorporation as well. Compared to sample A, only with cement of $15 \%$, samples (C, D, E), with different basalt fiber incorporations have the detailed growth rates of compressive strength. Just like at $7 \mathrm{~d}$ ages, with the equal basalt fiber increment, the first $0.5 \%$ increment of basalt fiber has the greatest growth rate of compressive strength and obvious strengthening effects, with the strengthening efficiency of reinforced fiber steadily decreasing.

(3) At the ages of 60d and 90d, it can be inferred from the experimental results that with the better effects of cement hydration and hardening the interface friction between cemented soil and basalt fiber enhances greatly and the strengthening effects of basalt fiber on compressive strength of cemented soil are well demonstrated. Same to the ages of $7 \mathrm{~d}$ and $28 \mathrm{~d}$, with the increase of basalt fiber incorporation, the compressive strength of cemented soil enhances gradually as well and, with 
the equal increase of basalt fiber incorporation, the growth rate of compressive strength of cemented soil steadily slows down.

(4) In summary, the compressive strength of cemented soil enhances with the increase of cement basalt fiber incorporation and the latter has better strengthening efficiency than the former. It can be inferred from comparisons on the experimental results at each ages that the strengthening (reinforcement effects) of basalt fiber on compressive strength of cemented soil relies mainly on fiber incorporation, blocking the crack occurrence and development of cemented soil under stress impacts whereas enhancing the strength of cemented soil. The hydration and hardening of cement in cemented soil samples exert direct influences on the reinforcement of basalt fiber and, with the increase of ages, cement has better hydration and hardening, basalt fiber having greater reinforcement effects.

\section{Relations between Compressive Strength of Cemented Soil with Basalt Fiber and Ages}

Different from concrete, the strength of cemented soil enhances greatly after $28 \mathrm{~d}$ and gradually stabilizes at 90d, so the average compressive strength value of cemented soil at 90d ages should be the compressive strength value of the vertical load. Additionally, in practical projects, the inspection on cemented soil pile is generally done after its completion, but since cemented soil pile has the average compressive strength value of cemented soil at $90 \mathrm{~d}$ ages as the standard value of its vertical load, its standard strength value at $90 \mathrm{~d}$ cannot be obtained within a short ages, which requires relations between the strength of cemented soil at short ages and the standard strength at 90d ages for reference of the prediction of cemented soil strength. This paper adopts the power function relations between compressive strength of cemented soil and ages to conduct fitting analysis on the cemented soil samples with basalt fiber as shown in formula 2.

$$
\frac{q_{u 1}}{q_{u 2}}=\left(\frac{T_{1}}{T_{2}}\right)^{0.352}
$$

The squared value of correlation index in formula (2) $R^{2}=0.96, q_{u l}$ is the compressive strength of cemented soil with basalt fiber at a random ages, $q_{u l}$ is the compressive strength of cemented soil with basalt fiber at $90 \mathrm{~d}$ ages, $T_{1}$ is a random ages and $T_{2}$ is $90 \mathrm{~d}$ ages.

\section{Conclusions}

This paper mainly performs unconfined compressive strength test on cemented soil samples with basalt fiber of different proportions, the corresponding compressive strengths and different failure modes are obtained and the following conclusions are gotten by analyzing the experimental results:

1) Basalt fiber can greatly enhance the compressive strength of cemented soil samples. Within the experimental range, the increase of basalt fiber incorporation has better strengthening effects on cemented soil samples than that of cement incorporation and basalt fiber has higher strengthening efficiency by comparison.

2) The strengthening (reinforcement effects) of basalt fiber on the compressive strength of cemented soil largely relies on the increase of interface friction and bond stress between 
cemented soil particles after cement hydration and basalt fiber and, with the increase of ages, cement hydration and hardening betters, the reinforcement effects of basalt fiber enhancing significantly. Basalt fiber has great strengthening effect when fiber incorporation is $0.5 \%$ and the strengthening efficiency gradually weakens with the increase of incorporation.

3) Based on the experimental results, the relations between the compressive strength of cemented soil sample with basalt fiber and ages are established, which can provide some references for the strength prediction of cemented soil in practical projects.

\section{References}

[1] Singh S. P., Singh B. \& Kaushik S. K. 2005. Probability of Fatigue Failure of Steel Fibrous Concrete. Magazine of Concrete Research. 57(2) , p. 65-72.

[2] Jong S. S., Charlwood P. \& Do Y. M. 2005. Characteristics of basalt fiber as a strengthening material for concrete structures. Composites: Part B, 36(6) , p.504-510.

[3] WANG K. J., SHAH S. P.\& PHUAKSUK P. 2001. Plastic shringkage cracking in concrete materials-influence of fly ash and fibers.ACI Materials Journal, 98(6) , p. 28-34.

[4] Parviz S.\& Siavosh R. 2004. Control of Plastic Shrinkage Cracking with Specialty Cellulose Fibers.ACI Materials Journal, (4) , p.429-435.

[5] Bin W., Cao H. L.\& Song S. H. 2010. Environmental resistance and mechanical performance of basalt and glass fibers. Materials Science and Engineering A, 527(19) , p. 4708-4715.

[6] Marco D. L., Andrea P.\& Gaetano M. 2010. Structural upgrade using basalt fibers for concrete confinement. Journal Composites for Construction, 14(5) , p. 541-552. 